\title{
[TUGAS PEMROGRAMAN I Rumah sakit dasar]
}

NPM $\quad: 19421026$

NAMA : Ricky Tanrean

PRODI : INFORMATIKA

FAKULTAS : ILMU KOMPUTER

EMAIL : rickytanrean02@gmail.com

\section{SOAL TUGAS :}

1. Buatlah Program dengan ketentuan sebagai berikut :

Input :

kode pasien $=$ PS0003

Kode Kamar $=\mathbf{4 4 4 4 4}$

Lama Menginap = 5 hari

Kode Dokter $=$ DK003

\begin{tabular}{|l|l|l|}
\hline Kode Pasien & Status Pasien & Biaya Daftar Pasien \\
\hline PS0001 & Pasien Baru & Rp. 500.000 \\
\hline PS0002 & Pasien Lama & Rp. 400.000 \\
\hline PS0003 & Pasien BPJS & Rp. 300.000 \\
\hline PS0004 & Pasien Askes & Rp. 200.000 \\
\hline
\end{tabular}

\begin{tabular}{|l|l|l|}
\hline Kode Kamar & Nama Kamar & Biaya Kamar \\
\hline 1111 & Kamar Melati & Rp. 1.000 .000 \\
\hline 2222 & Kamar Mawar & Rp. 2.000 .000 \\
\hline 3333 & Kamar Dahlia & Rp. 3.000.000 \\
\hline 4444 & Kamar Anggrek & Rp. 4.000.000 \\
\hline 5555 & Kamar Tulip & Rp. 5.000.000 \\
\hline
\end{tabular}

\begin{tabular}{|l|l|}
\hline Lama Menginap & Diskon \\
\hline$>10$ Hari & $50 \%$ dari Biaya Kamar \\
\hline$>8$ Hari & $40 \%$ dari Biaya Kamar \\
\hline$>6$ Hari & $30 \%$ dari Biaya Kamar \\
\hline$>4$ Hari & $20 \%$ dari Biaya Kamar \\
\hline$>+1$ & $10 \%$ dari Biaya Kamar \\
\hline
\end{tabular}

\begin{tabular}{|l|l|l|}
\hline Kode Dokter & Nama Dokter & Biaya Pemeriksaan \\
\hline DK001 & DR. Andi & Rp. 500.000 \\
\hline DK002 & DR. Joko & Rp. 400.000 \\
\hline DK003 & DR. Karni & Rp. 300.000 \\
\hline DK004 & DR. Amin & Rp. 200.000 \\
\hline DK005 & DR. Udin & Rp. 100.000 \\
\hline
\end{tabular}


Total Bayar = Biaya Daftar Pasien + Biaya Kamar + Biaya Pemeriksaan - Diskon Output (Tampilkan) $=$

Status Pasien

Biaya daftar Pasien

Nama Kamar

Biaya Kamar

Nama Dokter

Biaya Pemeriksaan

Diskon

Total Bayar

SOURCE CODE / KODING PROGRAM (KETIK DIBAWAH INI)

public class dokter \{

public static void main(String[]args) \{

String kode="PS0003";

String StatusPasien;

double BiayaDaftar;

double KodeKamar=4444;

String NamaKamar;

double BiayaKamar;

String KodeDokter="DK003";

String NamaDokter;

int BiayaPemeriksaan;

double lamamenginap $=5$;

double hasildiskon;

double diskon;

double TotalBayar;

if(kode=="PS0001")\{

StatusPasien="Pasien Baru";

BiayaDaftar=500000; 


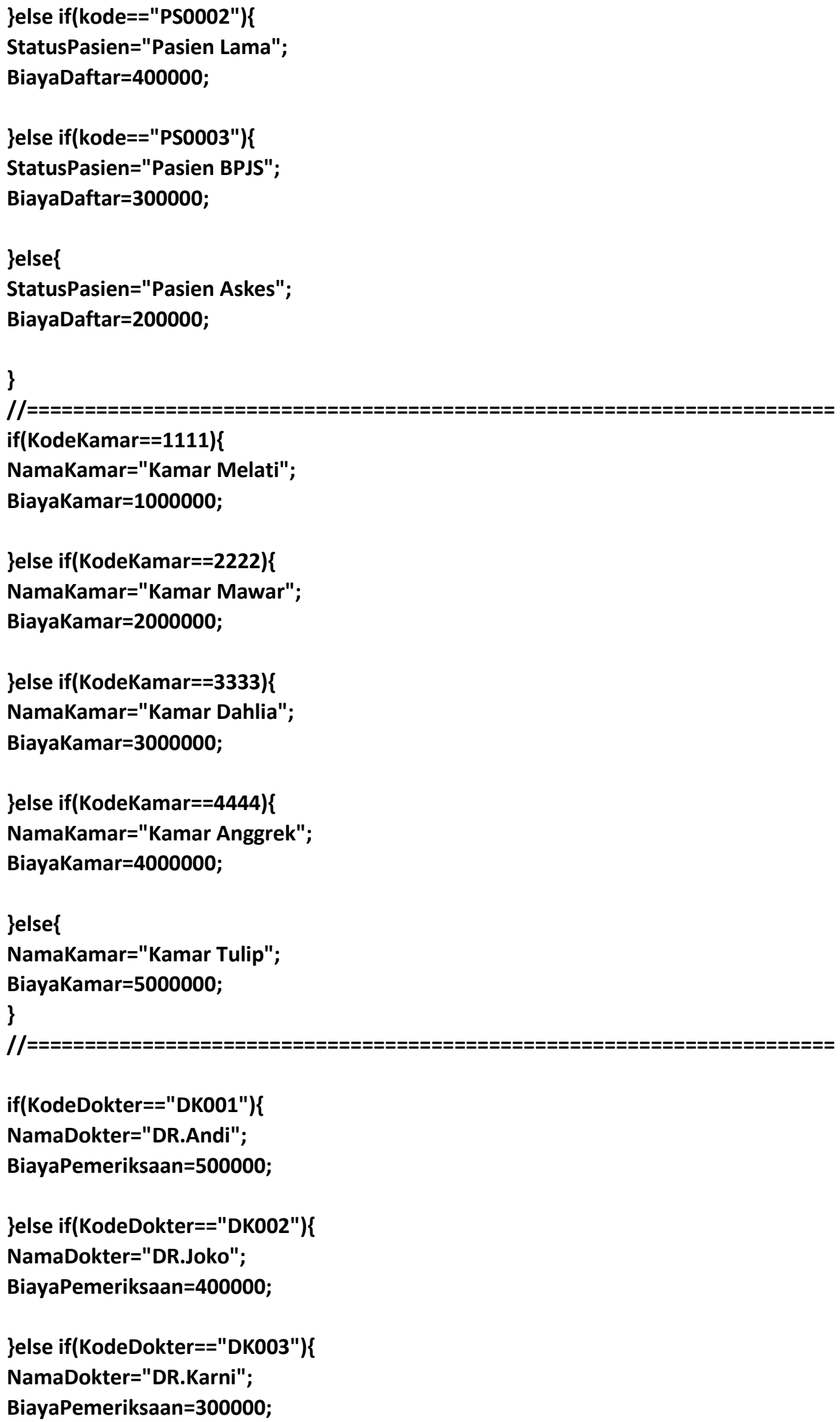




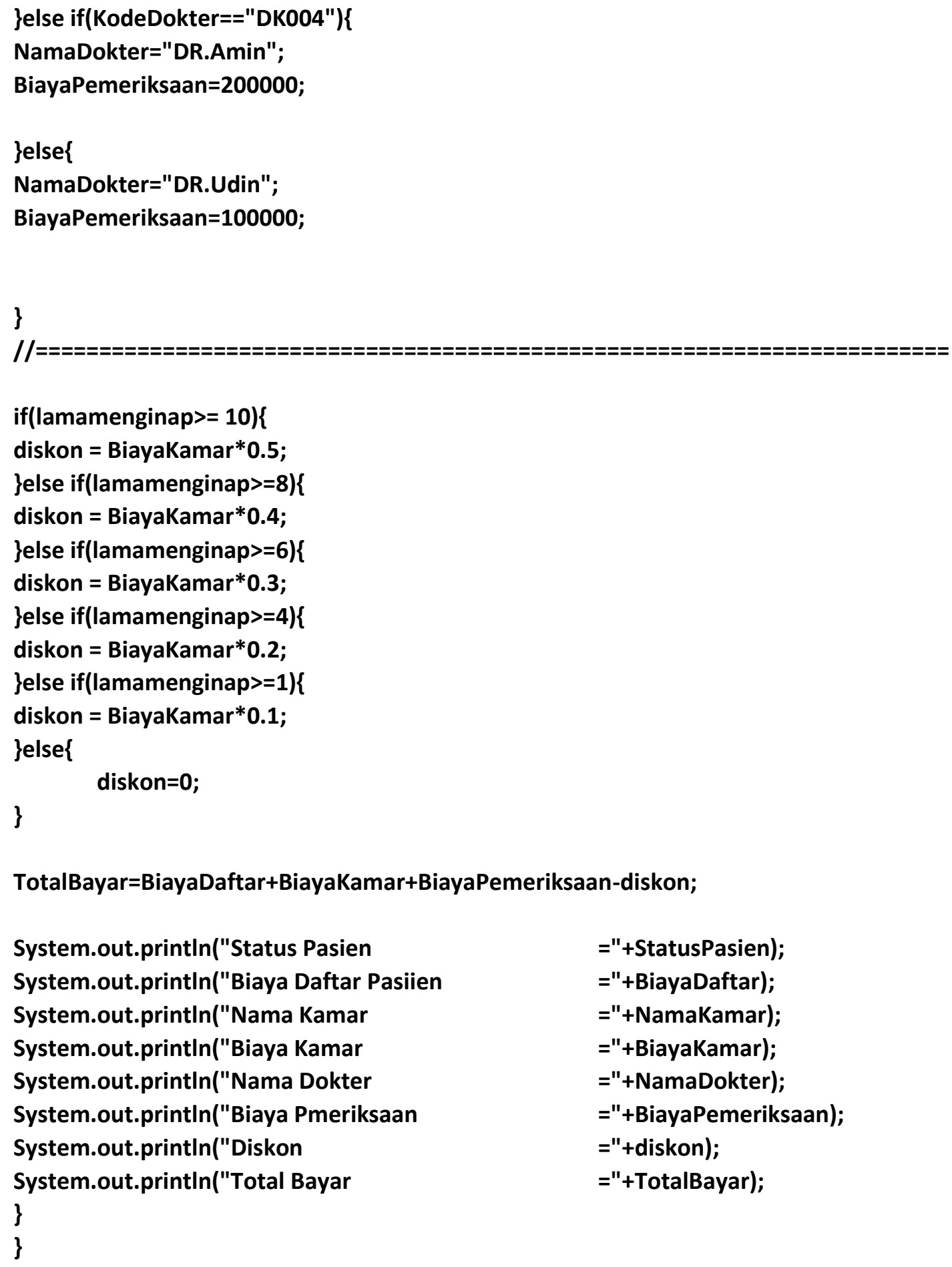

TotalBayar=BiayaDaftar+BiayaKamar+BiayaPemeriksaan-diskon;

System.out.printIn("Status Pasien

System.out.printIn("Biaya Daftar Pasiien System.out.printIn("Nama Kamar System.out.printIn("Biaya Kamar System.out.printIn("Nama Dokter System.out.printIn("Biaya Pmeriksaan System.out.printIn("Diskon System.out.printIn("Total Bayar \} \} 
PENJELASAN SOURCE CODE (KETIK DIBAWAH INI)

public class dokter \{

Public class (NamaClass) \{

Public class berfungsi untuk memberikan nama kelas yang akan dibuat

public static void main(String[]args) \{

Public static void main(String []args)\{

Berupa array dengan tipe data String.

String adalah tipe data untuk teks yang merupakan gabungan huruf, angka, whitespace(spasi), dan berbagai karakter.

Double adalah tipe data untuk angka, sama seperti int, tapi double dapat menggunakan koma dan tipe data meruakan 64bit.

Pernyataan if mempunyai pengertian, "Jika kondisi bernilai benar, maka perintah-1 akan dikerjakan dan jika tidak memenuhi syarat maka akan mengerjakan perintah-2 dan seterusnya

Type data String, double, int, dan tipe data lainya dapat di panggil dengan perintah penambahan + dalam system.out.println("contoh $\quad=$ "+BiayaDaftar);

Contoh memanggil type data String dan double

Juga pemakaian kondisi if dan else dalam pembuatan program

Jika kode di atas yang dimasukan dalam type data String="PS0001"; maka tampilan status pasien yang akan di keluarkan program adalah "Pasien Baru, dan 500000 dst.

Sedangkan String di atas yang di minta adalah PS0002

Maka kondisi yang dikeluarkan adalah isi data PS0002

\section{Diskon}

Diskon di dapat jika lamamenginap lebih dari 10 maka diskon di dapat dari

Biayakamar*0.5 Dan seterusnya sesuai program yang diminta 


\section{FLOWCHART PROGRAM CODING}

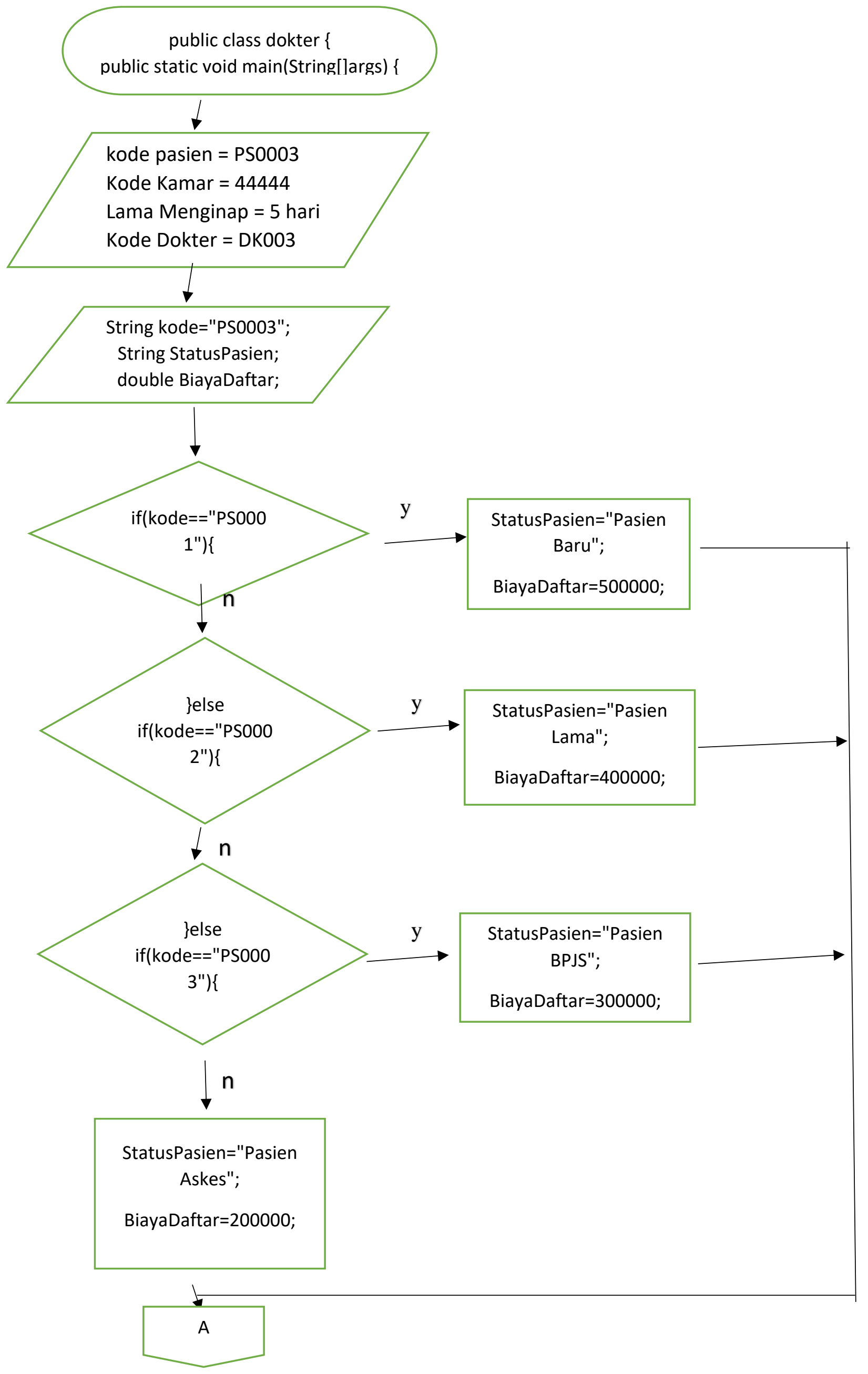




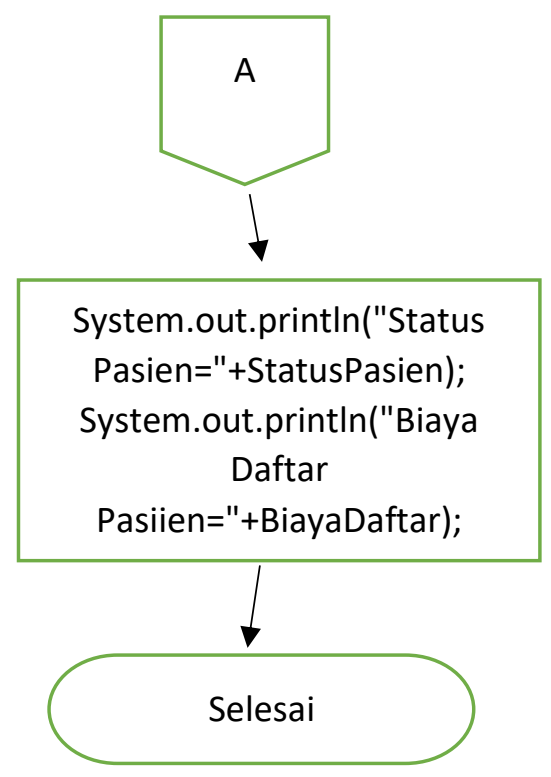

MOHON MAAF HANYA DI BUAT 1 CODING FLOWCHART 


\section{FLOWCHART PROGRAM}

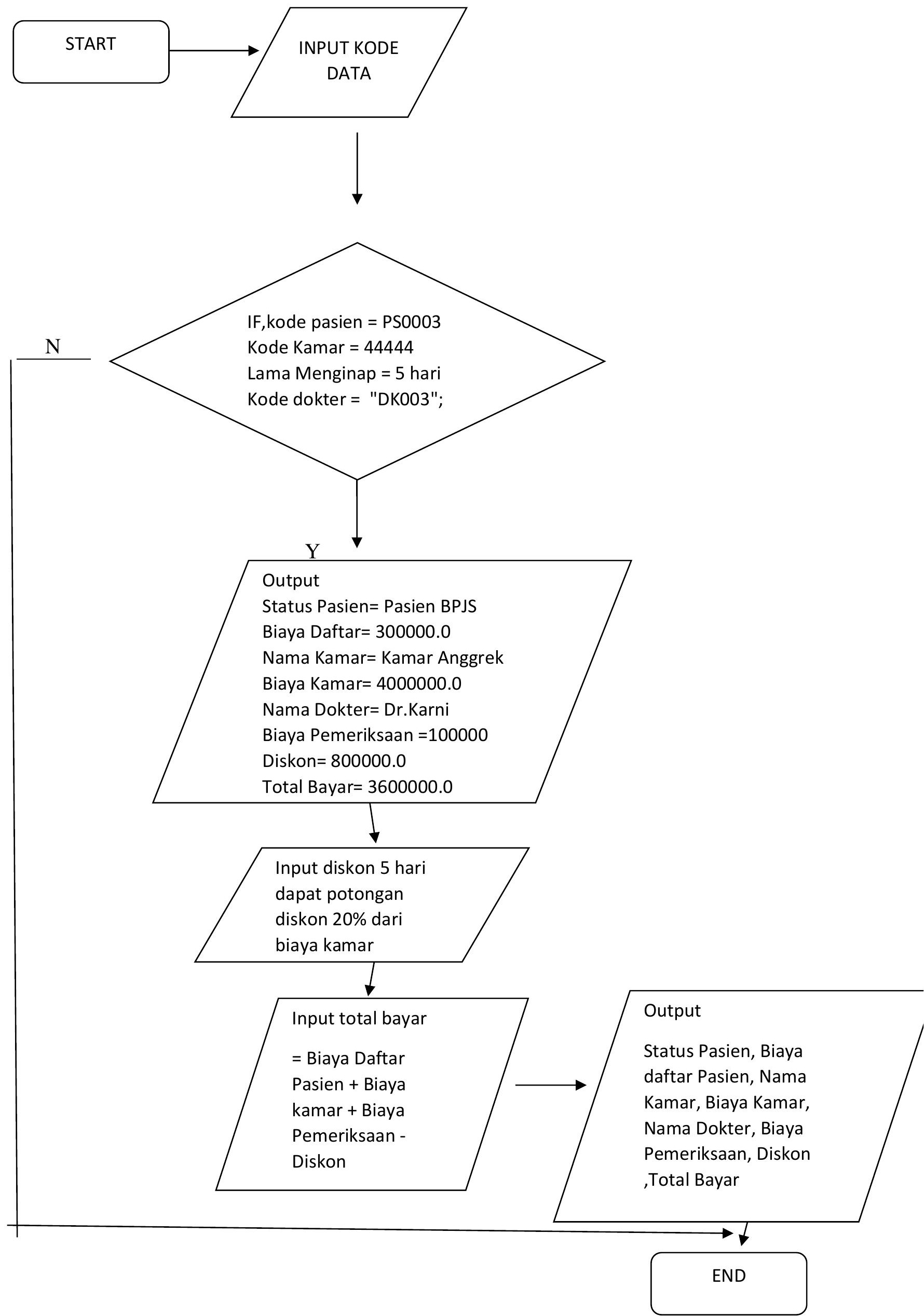




\section{REFERENSI :}

Endra, R. Y. (2019, October 29). Belajar Mudah Algoritma dan Pemograman Java. Retrieved from osf.io/v7yfn

Endra, R. Y. (2019, October 29). Internet of Things. Retrieved from osf.io/4h8sf

Google (https://www.petanikode.com/cpp-percabangan/, https://ndoware.com/diagram-alirflowchart.html)

Kreativitas otak saya dalam merangkum (Walau tidak terlihat kreatif) :) 